\title{
Effect of Extrusion Temperature on Microstructure and Biodegradation Behavior of Mg-5Zn-1Y-1Ca Alloy
}

\author{
H. Jafari and F. Doost Mohammadi
}

\begin{abstract}
In this years, many researches on the biodegradable behavior of $\mathrm{Mg}$ and its alloys has been done. Low corrosion resistance of the magnesium alloys has led to search a new generation of magnesium alloys for better strength, ductility, and high corrosion resistance. In this study, Mg-5Zn-1Y-1Ca alloy was fabricated by melting process and hot extrusion (at 300,330 and $370{ }^{\circ} \mathrm{C}$ ). The effect of temperature of extrusion on microstructure and degradation behavior of Mg-5Zn-1Y-1Ca alloy were investigated by optical microscopy, scanning electron microscopy with an energy dispersive $\mathrm{X}$-ray spectroscopy, $\mathrm{X}$-ray diffraction, immersion test and electrochemical test. The results showed that Mg-ZnY-Ca alloy was composed of $\alpha-\mathrm{Mg}, \mathrm{Mg}_{3} \mathrm{YZn}_{6}$ phase and $\mathrm{Ca}_{2} \mathrm{Mg}_{6} \mathrm{Zn}_{3}$ particles. Immersion and electrochemical tests showed that extruded Mg-5Zn-1Y-1Ca alloy at $330{ }^{\circ} \mathrm{C}$ exhibited the best degradation resistance from other alloys in this study.
\end{abstract}

Index Terms-Magnesium alloys, extrusion, microstructure, biodegradable, degradation.

\section{INTRODUCTION}

Magnesium, with a density of $1.74 \mathrm{~g} / \mathrm{cm}^{3}$, is the lightest structural metals. Its low density encourages different industries such as automotive, aerospace, military, medical, etc. to use this metal in different applications [1]. Biocompatibility, biodegradability and elastic modulus close to natural bone have made magnesium as an appropriate candidate in the medical industry to be fabricated as the orthopedic implants. However, low corrosion resistance and mechanical properties of this metal persuades the researchers to utilize different techniques such as alloying, heat treatment, thermomechanical treatment and coating, to improve its properties [2]-[5]. Alloying elements, including $\mathrm{Al}, \mathrm{Zn}, \mathrm{Mn}, \mathrm{Ca}, \mathrm{Y}, \mathrm{Zr}$ and Rare earth (RE) are the common elements that are usually used to improve the corrosion and mechanical properties of magnesium alloys [6], [7]. However, in order to fabricate orthopedic implant the alloying elements must be carefully chosen to maintain the biocompatibility of magnesium. For instant $\mathrm{Al}$ as the main alloying element in magnesium, has been linked to Alzheimer's disease [8]. Ca [9] and Zn [10] are two basic elements in the human body that improve the mechanical strength of magnesium alloys. Ca as the main component of bone, has been reported to improve the corrosion resistance of magnesium alloys, and to accelerate bone formation [11], [12].

In addition to alloying, thermomechanical processes, such as extrusion, are simultaneously considered to improve magnesium properties. Xu et al. [13] studied the corrosion behavior of extruded Mg-Y alloys at two extrusion ratios with different percentages of $\mathrm{Y}$. They found that the microstructure of as-cast alloy completely disappeared after extrusion and the grains refined. They also reported that no passive zone was detected in polarization curves, meaning when the alloy is immersed in a solution $3 \% \mathrm{NaCl}$ the grain boundaries accelerated the corrosion process. They also reported that increasing extrusion ratio resulted in better corrosion resistance.

Similarly Zhang et al. [14] studied the effect of different amounts of $\mathrm{Y}$ on the corrosion behavior of the extruded magnesium alloy. They found that an increase in $\mathrm{Y}$ content, especially after the extrusion which refined the microstructure, decreased corrosion resistance of the alloy. Zeng et al. [15] investigated the microstructure and corrosion behavior of extruded Mg-Ca alloys with different percentages of $\mathrm{Ca}$ alloying element. They reported microstructure evolution of binary Mg-Ca alloys with the recrystallized fine grains and a considerable volume of dispersed $\mathrm{Mg}_{2} \mathrm{Ca}$ particles. It was shown that increasing $\mathrm{Ca}$ content refined the grain size which improved corrosion resistance. However, an increase in $\mathrm{Mg}_{2} \mathrm{Ca}$ volume fraction increases the corrosion rate due to the galvanic effect between $\mathrm{Mg}_{2} \mathrm{Ca}$ phase and $\alpha-\mathrm{Mg}$ matrix. Sun et al. [16] studied the effect of extrusion temperature on the microstructure and mechanical properties of $\mathrm{Mg}-3.0 \mathrm{Zn}$ $0.2 \mathrm{Ca}-0.5 \mathrm{Y}$ alloy. The alloy was extruded at different temperatures and at a fixed extrusion rate and ratio. It was shown that increasing extrusion temperature recrystallized the elongated grains and their fraction was increased. Considering the reported literature, it can be found that no research can be found that investigates the effect of extrusion temperature on the corrosion behavior of magnesium alloys. Therefore, this study focuses on the effect of different temperatures of 300,330 and $370^{\circ} \mathrm{C}$ on biodegradation of Mg-5Zn-1Y-1Ca alloy.

\section{EXPERIMENTAL PROCEDURE}

\section{A. Materials Preparation}

To prepare Mg-5Zn-1Y-1Ca alloy, commercially pure ingots of magnesium, zinc, calcium and Mg-30\%Y master alloy were used. First, magnesium ingots were charged into graphite crucible and melted using an induction furnace.
Manuscript received April 16, 2017; revised July 20, 2017. The authors are with Shahid Rajaee Teacher Training University (SRTTU), Tehran, 16785-136 Iran (e-mail: hjafari@srttu.edu, fereshteh_dm91@yahoo.com). 
Then the calculated amounts of $\mathrm{Ca}$ and $\mathrm{Zn}$ ingots and Mg$30 \% \mathrm{Y}$ master alloy were added to the molten magnesium having $740^{\circ} \mathrm{C}$ at an interval of $5 \mathrm{~min}$, while the molten alloy was heated and stirred by a quartz rod. After a few minutes, the prepared molten alloy was gravity cast into a simple cylindrical steel mold with a dimension of $30 \mathrm{~mm} \times 130 \mathrm{~mm}$ that preheated to $100{ }^{\circ} \mathrm{C}$. All stages of melting, alloying and casting were done under a shielding gas of Ar. Inductively coupled plasma-optical emission spectrometry (ICP-OES) was used to determine the chemical composition of the fabricated alloy. In order to change the dendritic structure and to provide a homogenous and uniform structure, the cast samples were heat treated at $385^{\circ} \mathrm{C}$ for 18 hours.

The homogenized samples with a dimension of $30 \mathrm{~mm} \times$ $30 \mathrm{~mm}$ were heated to 300,330 and $370{ }^{\circ} \mathrm{C}$ temperature and kept for 1 hour prior to extrusion. The extrusion processes was performed using a 100-ton press while the extrusion ram speed was set to $1 \mathrm{~mm} / \mathrm{s}$ and the extrusion ratio was 1:6. Then the products were cooling to room temperature on the air.

\section{B. Microstructural Characterization}

Specimens were cut from the as-cast and extruded samples for the microstructure characterization. The specimens were ground with $\mathrm{SiC}$ papers up to a final 2500 grit, then polished using diamond paste followed by etching using the Nital etchant for $20 \mathrm{~s}$. An optical microscope (OM, Aristomet), an scanning electron microscope (SEM, MIRA3 Tescan) equipped with an energy dispersive X-ray spectroscopy (EDS) device, and an X-ray diffraction (XRD, JEDL, JDX-8030) technique were utilized to observe and characterize the microstructure of the extruded samples. The average grain size of the samples was determined using the linear intercept procedure according to the standard ASTM E112-96.

\section{Corrosion Behavior}

To evaluate the degradation properties of the as-cast and extruded samples in simulated body fluid (SBF), electrochemical polarization and immersion tests were performed. The SBF was prepared by dissolving the high purity grade of chemical materials and with the order given in Table I. The chemicals were dissolved in $700 \mathrm{ml}$ of double distilled water at $36.5{ }^{\circ} \mathrm{C}$ under constant stirring followed by adjusting the $\mathrm{pH}$ to 7.4 using a $\mathrm{pH}$ meter (SANA SL-901) and making the fluid up to $1 \mathrm{~L}$.

A potentiostat/galvanostat apparatus (BHP 2064) connected to a PC with a scan rate of $1 \mathrm{mV} / \mathrm{s}$ started from 2.5 to $-1 \mathrm{~V}$ was used for the experiment. A standard cell consisting of three electrodes of the working electrode (a specimen sized $1 \mathrm{~cm}^{2}$ cut parallel to the extrusion direction and ground with SiC papers up to a final 2500 grit), saturated calomel electrode (SCE), counter electrode (platinum electrode), containing $50 \mathrm{ml} \mathrm{SBF}$ with $\mathrm{pH}$ of 7.40 at $37{ }^{\circ} \mathrm{C}$ was used to do the experiment. Excel software was used to process the recordings. The data was saved as curve and excel files. Using corrosion current density $\left(i_{\text {Corr }}, \mathrm{A} / \mathrm{cm}^{2}\right)$ extracted from polarization curves, corrosion rate $\left(P_{i}\right.$, mpy) was calculated by Eq. (1).

$$
P_{i}=2.285 \times 10^{4} \times i_{\text {Corr }}
$$

Immersion test was conducted according to the ASTMG31-72. Specimens, measuring $10 \mathrm{~mm}$ diameter and $10 \mathrm{~mm}$ length, from the as-cast and extruded alloy were cut and ground up to 2500 grit by SIC papers; then were cleaned, washed with distilled water, rinsed, dried using blowing hot air, and weighted. Afterward, they were immersed into a beaker containing $200 \mathrm{ml} \mathrm{SBF}$ for $165 \mathrm{~h}$. In an interval of 24 $h$, the specimens were removed from SBF and were immersed in $18 \mathrm{gr} / \mathrm{L}$ chromic solution for 2 minutes to remove the corrosion products. After rinsing and drying, the specimens were reweighted to measure the weight loss. Corrosion rate (mpy) obtained from the immersion test was calculated using Eq. (2).

TABLE I: CHEMICAL MATERIALS USED FOR PREPARING SBF FOR ONE LITER [17]

\begin{tabular}{ccc}
\hline \hline Order & Chemical materials & Amount (g/L) \\
\hline \hline 1 & $\mathrm{NaCl}$ & 8.035 \\
2 & $\mathrm{NaHCO}_{3}$ & 0.355 \\
3 & $\mathrm{KC}_{1}$ & 0.225 \\
4 & $\mathrm{~K}_{2} \mathrm{HPO}_{4} 3 \mathrm{H}_{2} \mathrm{O}$ & 0.231 \\
5 & $\mathrm{MgCl}_{2} 6 \mathrm{H}_{2} \mathrm{O}$ & 0.311 \\
6 & $1 \mathrm{M}-\mathrm{HCl}$ & $39 \mathrm{ml}$ \\
7 & $\mathrm{CaCl}_{2}$ & 0.292 \\
8 & $\mathrm{Na}_{2} \mathrm{SO}_{4}$ & 0.072 \\
9 & $\left(\mathrm{CH}_{2} \mathrm{OH}\right)_{3} \mathrm{CNH}_{2}$ (Tris) & 6.118 \\
10 & $1 \mathrm{M}-\mathrm{HCl}$ \\
\hline \hline
\end{tabular}

$$
\mathrm{CR}(\mathrm{mpy})=\frac{\mathrm{KW}}{\mathrm{DTA}}=\frac{8.76 \times 10^{4} \mathrm{~W}}{\mathrm{DTA}}
$$

In this equation, $\mathrm{W}$ is the weight loss in gr, $\mathrm{D}$ is density of alloy in $\mathrm{gr} / \mathrm{cm}^{3}$, A is surface area in $\mathrm{cm}^{2}$ and $\mathrm{T}$ is immersion time in $\mathrm{h}$.

The electrochemical polarization and immersion tests were repeated for three and two times, respectively to obtain reliable results.

\section{RESUlTS AND DisCUSSION}

\section{A. Chemical Composition of the Cast Alloy}

The chemical composition of the cast alloy is given in Table II. It can be seen that the chemical composition approves the nominal composition of the alloy, confirming the appropriate fabrication process.

\begin{tabular}{cc} 
TABLE II: CHEMICAL COMPOSITION OF THE CAST ALLOY \\
\hline \hline Element & Amount (wt \%) \\
\hline \hline $\mathrm{Zn}$ & 4.549 \\
$\mathrm{Y}$ & 0.908 \\
$\mathrm{Ca}$ & 1.036 \\
$\mathrm{Fe}$ & 0.003 \\
$\mathrm{Mn}$ & 0.005 \\
$\mathrm{Al}$ & 0.066 \\
$\mathrm{Cu}$ & 0.008 \\
$\mathrm{Si}$ & 0.006 \\
$\mathrm{Mg}$ & $\mathrm{Bal}$. \\
\hline \hline
\end{tabular}

\section{B. The Microstructure of the as-Cast and Extruded Alloy}

Fig. 1 shows OM as well as SEM images of the as-cast Mg-5Zn-1Y-1Ca alloy. As can be seen from Fig. 1(a), the 
microstructure of this alloy consists of continuous precipitations and dendritic structure within the grains. This is due to the non-equilibrium solidification of the alloy occurred during cooling to room temperature. Fig. 1(b) shows the SEM microstructure of the as-cast alloy. It displays a structure with lots of precipitates throughout of the alloy.
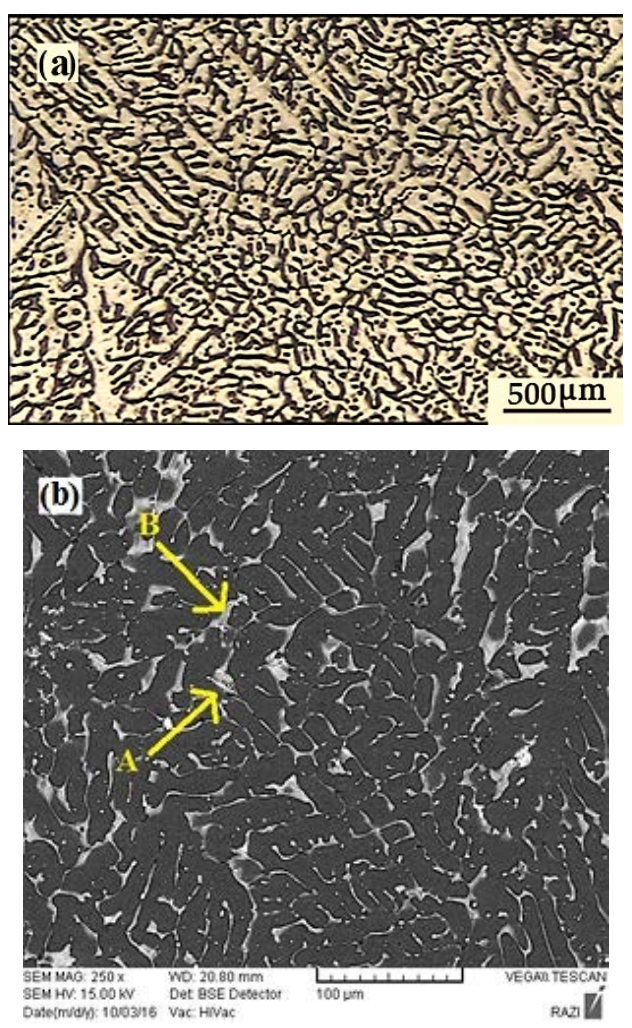

Fig. 1. Microstructure of the alloy; (a) OM image of the as-cast and (b) SEM image of the as cast Mg-5Zn-1Y-1Ca alloy.
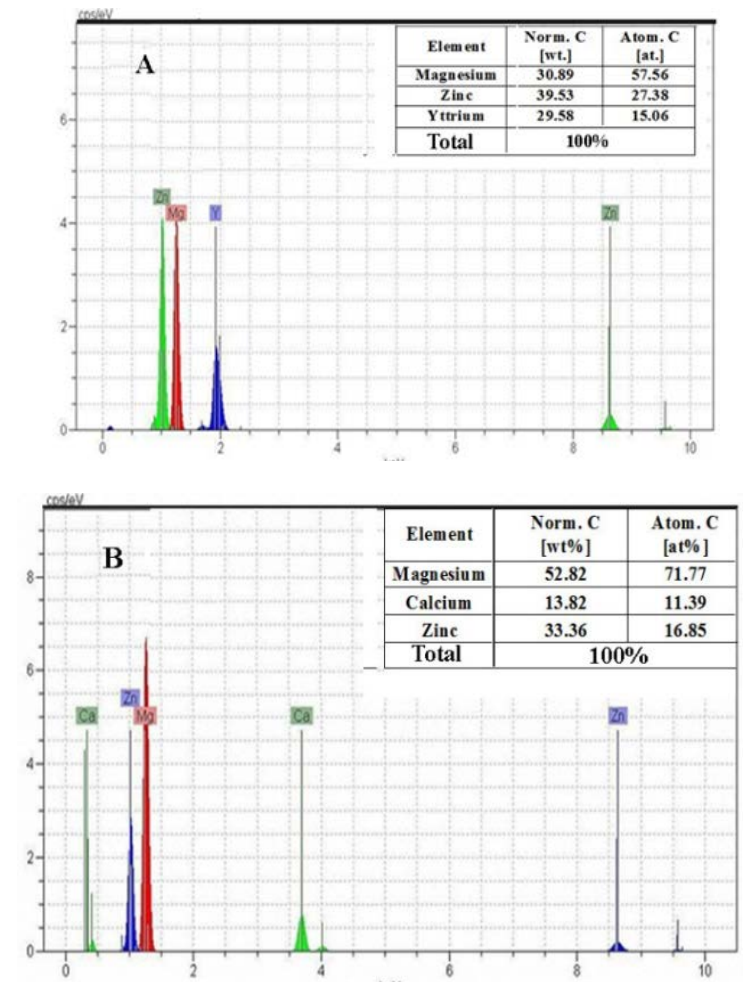

Fig. 2. EDS analysis of two points (a) A and (b) B specified in Fig. 1(b).

According to EDS analysis of the areas pointed with the letter A and B (Fig. 2), the alloy consists of two different intermetallic phases namely Mg3Zn6Y (I-phase) and $\mathrm{Ca}_{2} \mathrm{Mg}_{6} \mathrm{Zn}_{3}$ phase, respectively. According to reported results, weight ratio of $\mathrm{Zn} / \mathrm{Y}$ and atomic ratio of $\mathrm{Zn} / \mathrm{Ca}$ are very important in the formation of intermetallic phases in magnesium alloys [18]. If the weight ratio of $\mathrm{Zn} / \mathrm{Y}$ is higher than 4.38, I-phase is precipitated [19].

On the other hand, if the atomic ratio of $\mathrm{Zn} / \mathrm{Ca}$ is higher than 1.23, then $\mathrm{Ca}_{2} \mathrm{Mg}_{6} \mathrm{Zn}_{3}$ phase is formed; and if the ratio is less than this value, in addition to the formation of $\mathrm{Ca}_{2} \mathrm{Mg}_{6} \mathrm{Zn}_{3}$, the extra calcium will precipitate as $\mathrm{Mg}_{2} \mathrm{Ca}$ phase [18]. According to the results of ICP analysis, weight ratio of $\mathrm{Zn} / \mathrm{Y}$ is 5.10 and atomic ratio of $\mathrm{Zn} / \mathrm{Ca}$ is 2.69 , which confirm the formation of $\mathrm{I}$ and $\mathrm{Ca}_{2} \mathrm{Mg}_{6} \mathrm{Zn}_{3}$ phases in the microstructure that is quite similar to the result of XRD shown in Fig. 3.

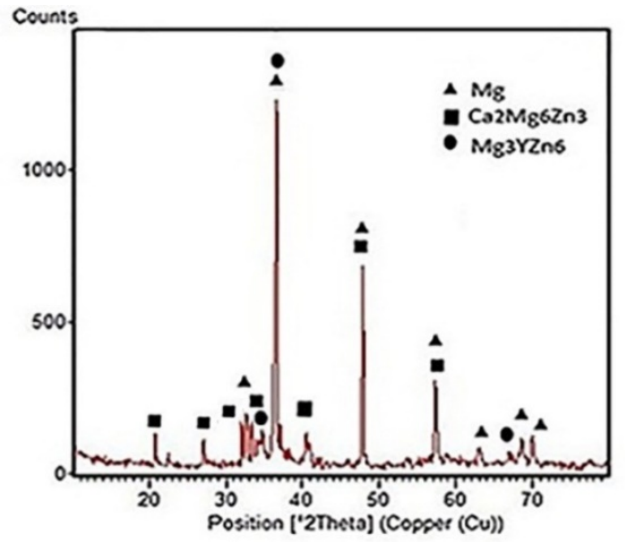

Fig. 3. The result of XRD analysis for the cast alloy.

Fig. 4 shows the OM image of the extruded alloys at different temperatures. Elongated pattern can be seen for the precipitates and intermetallic phases in all samples. It is believed that the extrusion force does not have the ability to break the precipitates during extrusion.

In addition, since the size of precipitates is higher than $1 \mu \mathrm{m}$, the interface of precipitates and matrix can be the local area for nucleation of dynamic recrystallized (DRXed) grains. In other words, dislocations are piled-up at the interface of precipitates and matrix and are rearranged at this location, leading to the formation of one DRX nuclei. This phenomenon is called particle stimulated nucleation (PSN). It is worth noting that the recrystallization behavior for a microstructure having high density of dislocations is not similar at different temperatures.

DRX grains between the precipitates is finer and their number is higher in the sample extruded at $300{ }^{\circ} \mathrm{C}$ (Fig. 4(a)) than those extruded at 370 and $330{ }^{\circ} \mathrm{C}$ (Fig. 4(b \& c), respectively). In contrast, a decreased in the number of DRXed grains and a better continuity can be seen in the sample extruded at $330{ }^{\circ} \mathrm{C}$ (Fig. 4(b)), while the DRXed grains are bigger in the sample extruded at $370{ }^{\circ} \mathrm{C}$ (Fig. 4(c)). Fig. 5 shows SEM images of the extruded samples. Looking at the SEM images, it can be observed that the Iphase (shown by letter A) have been broken along the extrusion direction while the $\mathrm{Ca}_{2} \mathrm{Mg}_{6} \mathrm{Zn}_{3}$ phase (shown by letter B) just elongated along it.

\section{Biodegradation Behavior of as-Cast and Extruded Alloys}

Fig. 6 and Table III provides the polarization curves of as- 
cast and extruded alloys and electrochemical parameters extracted from the curves, respectively.
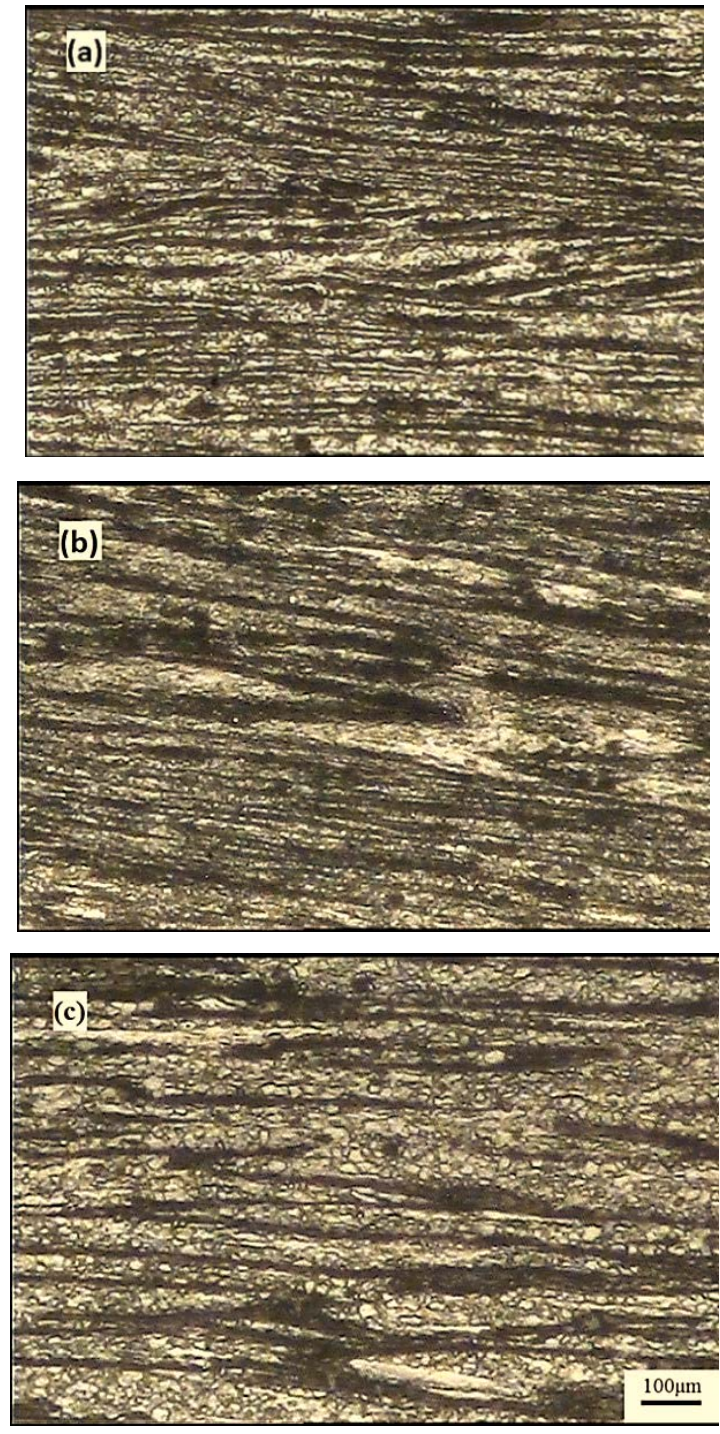

Fig. 4. The optical microscopy image of extruded alloys at different temperatures, extruded alloy at (a) 300, (b) 330 and (c) $370^{\circ} \mathrm{C}$.

Taking the results given in Table III into account, it can be seen that the corrosion potential of the samples are within a similar range. Therefore, in order to evaluate the degradation behavior, corrosion current density of the samples should be considered.

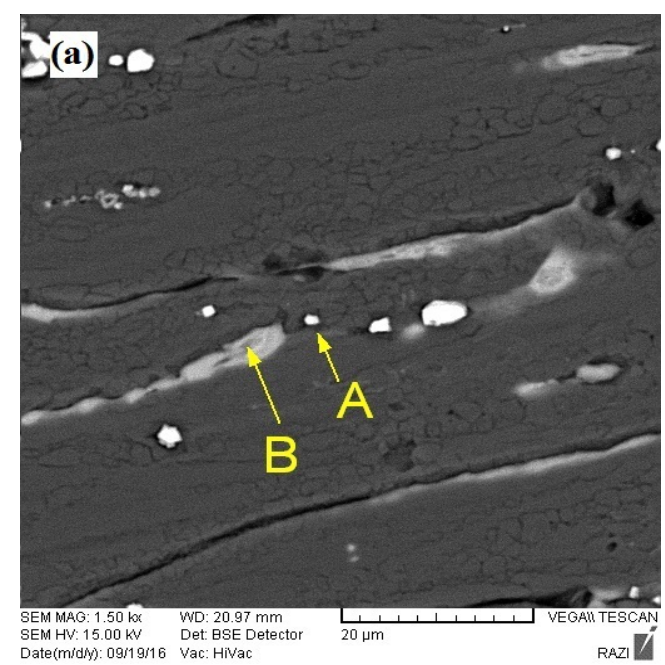

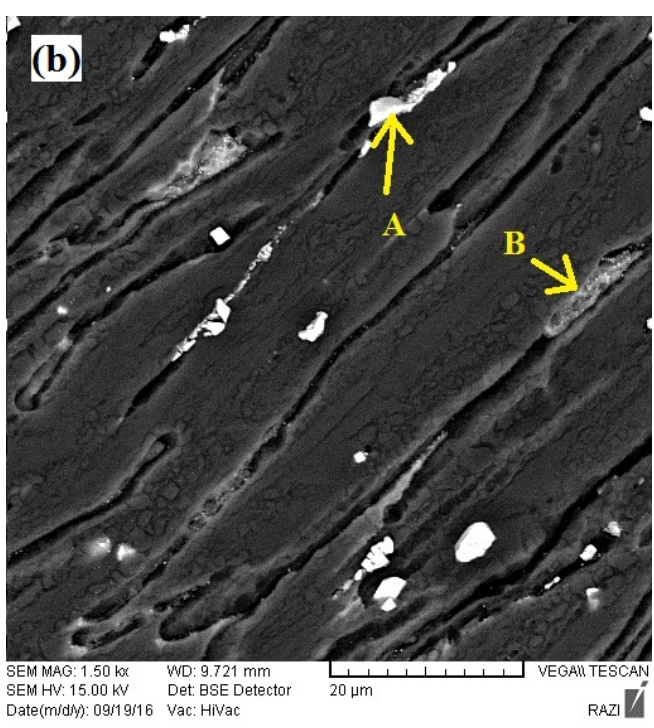

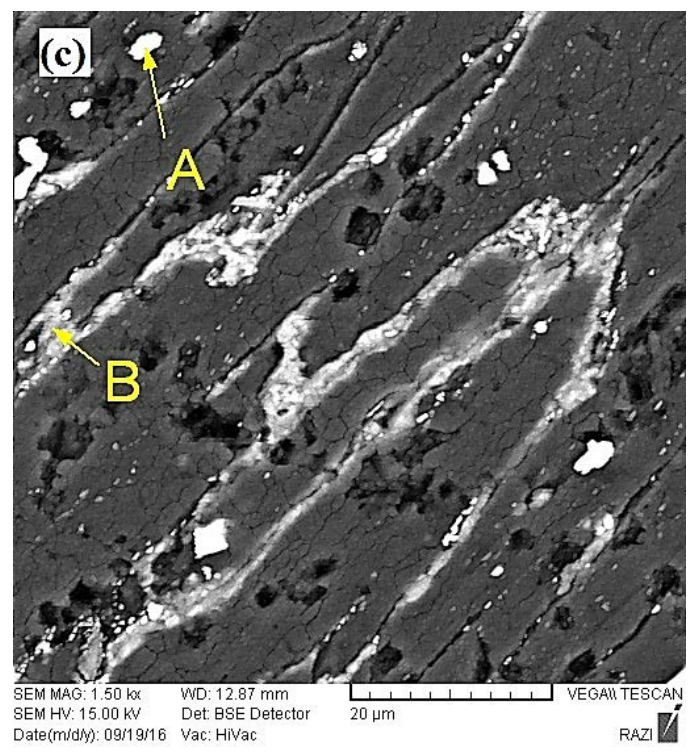

Fig. 5. SEM image of extruded alloy at (a) 300 , (b) 330 , and (c) $370{ }^{\circ} \mathrm{C}$.

There have been several studies which have investigated the effect of grain boundary on corrosion of magnesium alloys. Aung et al. [20] reported that grain boundary plays a role of physical barrier to inhibit corrosion of magnesium alloys. Modification of grain size causes creating more grain boundaries. As a result, corrosion rate of the fine-grained microstructures is less than the coarse-grained one. However, there are some researchers disagree with this idea as they believe that grain boundary is a crystal defect. For an instant, Song and $\mathrm{Xu}$ [21] reported that grain boundary is usually corroded at first; therefore, accelerates the corrosion rate, which is disagreement with Aung et al. [20] results. Xu et al. [13] believe that the effect of grain boundary on corrosion should be determined in the natural system.

When active corrosion is determined, refined grain size increases corrosion rate. As a result, when an alloy tends to be passivated, grain boundary aides the passivation process, therefore, refined grains which provide more boundary reduces corrosion rate of the alloy.

In the present study, the alloy, either in as-cast or extruded form did not show any passive mode when immersed in SBF. In other words, they exhibited active polarization behavior when they exposed to SBF. 


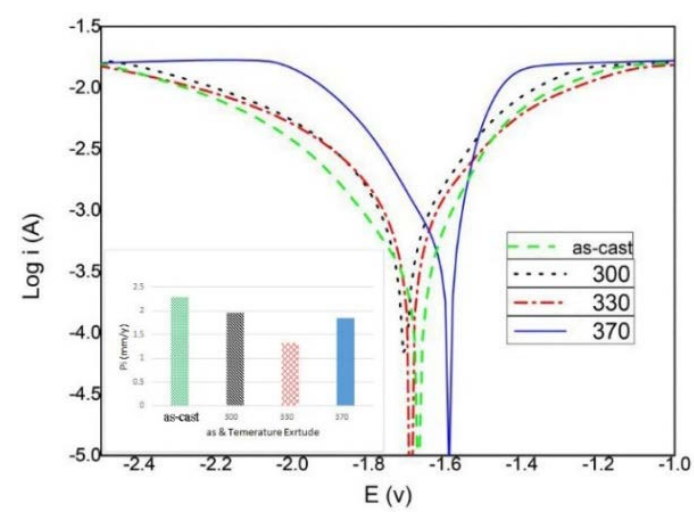

Fig. 6. Polarization curves of the as-cast and extruded samples.

TABLE III: ELECTROCHEMICAL PARAMETERS OF THE EXPERIMENTED SAMPLES

\begin{tabular}{ccccc}
\hline \hline & \multicolumn{4}{c}{ Samples } \\
$\begin{array}{c}\text { Electrochemical } \\
\text { parameters }\end{array}$ & as-cast & $300^{\circ} \mathrm{C}$ & $330^{\circ} \mathrm{C}$ & $370^{\circ} \mathrm{C}$ \\
\hline \hline$E_{\text {corr }}(\mathrm{v})$ & -1.654 & -1.705 & -1.690 & -1.589 \\
$I_{\text {corr }}\left(\mathrm{A} / \mathrm{Cm}^{2}\right) 10^{-5}$ & 10.030 & 8.541 & 5.818 & 8.092 \\
$P_{i}(\mathrm{~mm} / \mathrm{y})$ & 2.292 & 1.952 & 1.329 & 1.849 \\
\hline \hline
\end{tabular}

Thus although grain boundary obstructs the movement of dislocations, the dislocations are attacked by corrosion phenomenon and are not able to prevent it. As a result, it can be claimed that the higher the grain boundary, dislocation and twinning, the more the corrosion rate of magnesium alloys.

Extruded alloy at $330{ }^{\circ} \mathrm{C}$ behaved higher corrosion resistance compared to those extruded at other temperatures. This can be attributed to the microstructure of the extruded alloys which contains small number of DRXed grains and as a result have lower grain boundaries. In contrast, the alloy which was extruded at 300 and $370{ }^{\circ} \mathrm{C}$ experienced higher corrosion rates due to higher number of DRXed grains. On the other hand, secondary phase $\mathrm{Ca}_{2} \mathrm{Mg}_{6} \mathrm{Zn}_{3}$ is elongated along the extrusion direction without considerable being broken. So the amount of effective cathode is decreased and corrosion resistance is improved. Similar behavior has been reported by Tong et al. [22].

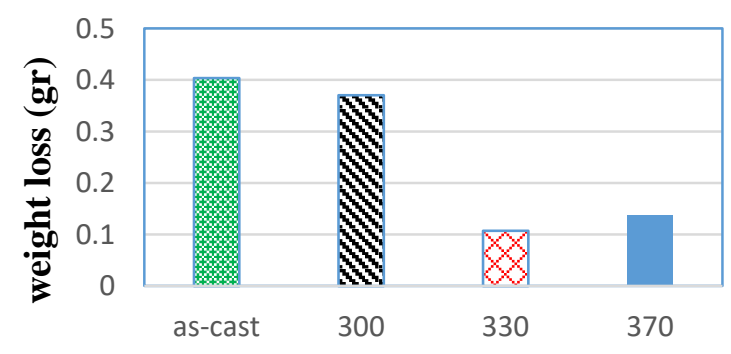

as-cast \& Extrusion temperature

Fig. 7. Weight loss chart of the as-cast and extruded samples at different temperatures.

Fig. 7 shows weight loss graph of the as-cast and extruded alloy at different temperatures after immersing for $165 \mathrm{~h}$ in SBF. It can be seen that extrusion process at all temperatures improved the corrosion resistance of the as-cast alloy. This is due to elongated $\mathrm{Ca}_{2} \mathrm{Mg}_{6} \mathrm{Zn}_{3}$ phase along the extrusion direction which decreased the volume of effective cathode leading to reduced corrosion rates. In addition, as the graph indicates, among the samples extruded at different temperatures, the one extruded at $330{ }^{\circ} \mathrm{C}$ experienced the lowest weight loss which is in good agreement with the results of polarization test.

\section{CONCLUSION}

The aim of this study was to investigate the effect of extrusion temperature on biodegradation properties of Mg5Zn-1Y-1Ca alloy. The following results can be drawn:

1. The microstructure of the as-cast Mg-5Zn-1Y-1Ca alloy consists of $\alpha-\mathrm{Mg}$ matrix and continuous secondary phases of $\mathrm{Ca}_{2} \mathrm{Mg}_{6} \mathrm{Zn}_{3}$ at grain boundaries and $\mathrm{Mg}_{3} \mathrm{YZn}_{6}$ with lamellar morphology located mostly at grain boundaries.

2. No passive behavior, but active polarization was observed in the as-cast and extruded alloys in SBF.

3. Extrusion process is able to reduce biodegradation rate of magnesium cast alloys in SBF. Extrusion at $330{ }^{\circ} \mathrm{C}$ produced a microstructure having lower number of DRXed grains with higher degradation resistance of Mg-5Zn-1Y1Ca alloy.

\section{ACKNOWLEDGMENT}

The authors wish to thank Shahid Rajaee Teacher Training University for the support in conducting this research.

\section{REFERENCES}

[1] H. E. Friedrich and B. L. Mordike, Magnesium Technology: Metallurgy, Design Data, Applications, Springer, 2006.

[2] M. P. Staiger, A. M. Pietaka, J. Huadmaia, and G. Dias, "Magnesium and its alloys as orthopedic biomaterials: A review," Biomater, vol. 27, no. 9, pp. 1728-1734, 2006.

[3] H. S. Brar, M. O. Platt, M. Sarntinoranont, P. I. Martin, and M. V. Manuel, "Magnesium as a biodegradable and bioabsorbable material for Medical implants,” JOM., vol. 61, no. 9, pp. 31-34, 2009.

[4] N. Nassif and I. Ghayad, "Corrosion protection and surface treatment of magnesium alloys used for orthopeadic applications," Adv. Mater. Sci. Eng., pp. 1-10, 2013.

[5] M. H. Idris, H. Jafari, S. E. Harandi, M. Mirshahi, and S. Koleyni, "Characteristics of as-cast and forged biodegradable Mg-Ca binary alloy immersed in Kokubo simulated body fluid," Adv. Mater. Res., vol. 445, pp. 301-306, 2012.

[6] H. Jafari, F. Rahimi, and Z. Sheikhsofl, "In vitro corrosion behavior of Mg-5Zn alloy containing low Y contents," Mater. Corr., vol. 67, no. 4, pp. 396-405, 2015.

[7] A. Myrissa, N. Ahmad Agha, Y. Lu, E. Martinelli, J. Eichler, G. Szakács, C. Kleinhans, R. Willumeit-Römer, U. Schäfer, and A. M. Weinberg, "In vitro and in vivo comparison of binary Mg alloys and pure Mg," Mater. Sci. Eng. C., vol. 61, pp. 865-874, 2016.

[8] D. Persaud-Sharma and A. McGoron, "Biodegradable magnesium alloys: A review of material development and applications," $J$. Biomim. Biomater. Tissue Eng., vol. 12, pp. 25-39, 2012.

[9] F. Qin, G. Xie, Z. Dan, S. Zhu, and I. Seki, "Corrosion behavior and mechanical properties of Mg-Zn-Ca amorphous alloys," Intermet., vol. 42, no. 11, pp. 9-13, 2013.

[10] N. Li and Y. Zheng, "Novel magnesium alloys developed for biomedical application: A review,” J. Mater. Sci. Tech., vol. 29, no. 6, pp. 489-502, 2013.

[11] L. B. Tong, M. Y. Zheng, S. W. Xu, X. S. Hu, K. Wu, S. Kamado, G. J. Wang, and X. Y. Lv, "Room temperature compressive deformation behavior of Mg-Zn-Ca alloy processed by equal channel angular pressing," Mater. Sci. Eng. A., vol. 528, no. 2, pp. 672-679, 2010.

[12] B. Zhang, Y. Hou, X. Wang, Y. Wang, and L. Geng, "Mechanical properties, degradation performance and cytotoxicity of Mg-Zn-Ca biomedical alloys with different composition,” Mater. Sci. Eng. C., vol. 31, no. 8, pp. 1667-1673, 2011.

[13] H. Xu, X. Zhang, K. Zhang Y. Shi, and J. Ren, "Effect of extrusion on corrosion behavior and corrosion mechanism of Mg-Y alloy,” J. Rare Earth., vol. 34, no. 3, pp. 315-327, 2016. 
[14] K. Zhang, X. Zhang, X. Deng, X. Li, and M. Ma, "Relationship between extrusion, $\mathrm{Y}$ and corrosion behavior of $\mathrm{Mg}-\mathrm{Y}$ alloy in $\mathrm{NaCl}$ aqueous solution,” J. Magnesium Alloy., vol. 1, no. 2, pp. 134-138, 2013.

[15] R. Zeng, W. Qi, H. Cui, F. Zhang, S. Li, and E. Han, "In vitro corrosion of as-extruded $\mathrm{Mg}-\mathrm{Ca}$ alloys-the influence of $\mathrm{Ca}$ concentration,"Corros. Sci., vol. 96, pp. 23-31, 2015.

[16] H. Sun, C. Li, and W. Fang, "Evolution of microstructure and mechanical properties of Mg-3.0Zn-0.2Ca-0.5Y alloy by extrusion at various temperatures,” J. Mater. Proc. Tech., vol. 229, pp. 63-640, 2016.

[17] E. Boccardi, A. Philippart, J. A. Juhasz-Bortuzzo, A. M. Beltrán, G. Novajra, C. Vitale-Brovarone, E. Spiecker, and A. R. Boccaccini, "Uniform surface modification of 3D Bioglass ${ }^{\circledR}$-based scaffolds with mesoporous silica particles (McM-41) for enhancing drug delivery capability,” Front. Bioeng. Biotechnol., vol. 3, pp. 1-12, 2015.

[18] Y. Z. Du, X. G. Qiao, M. Y. Zheng, D. B.Wang, K. Wua, and I. S. Golovin, "Effect of microalloying with Ca on the microstructure and mechanical properties of Mg-6 mass\%Zn alloys,” Mater. Design, vol. 98, pp. 285-293, 2016.

[19] M. Yang, D. Wu, M. Hou, and F. Pan, “As-cast microstructures and mechanical properties of $\mathrm{Mg}-4 \mathrm{Zn}-\mathrm{xY}-1 \mathrm{Ca}(\mathrm{x}=1.0,1.5,2.0,3.0)$ magnesium alloys,” Trans. Nonferrous Met. Soc. China, vol. 25, no. 3 , pp. 721-731, 2015 .

[20] N. N. Aung and W. Zhou, "Effect of grain size and twins on corrosion behaviour of AZ31B magnesium alloy,” Corros. Sci., vol. 52, no. 2, pp. 589-594, 2010.

[21] G. Song and Z. Xu, "The surface, microstructure and corrosion of magnesium alloy AZ31 sheet,” Electrochim. Acta, vol. 55, no. 13, pp. 4148-4161, 2010.
[22] L. B. Tong, Q. X. Zhang, Z. H. Jiang, J. B. Zhang, J. Meng, L. R. Cheng, and H. Zhang, "Microstructures, mechanical properties and corrosion resistances of extruded Mg-Zn-Ca-xCe/La alloys," J. Mech. Behav. Biomedic. Mater., vol. 62, pp. 57-70, 2016.

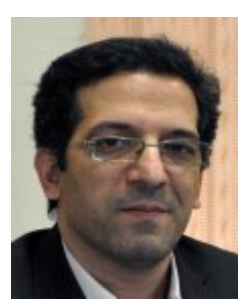

Hassan Jafari was born in Tehran, Iran, on April 21, 1969. In 1987, he enrolled in the Department of Materials Science and Engineering at Sharif University of Technology; he completed his BS in 1992 and MS in 1992. Following his graduation, Hassan Jafari was appointed as a lecturer in the Department of Materials Engineering, in Shahid Rajaee Teacher Training University (SRTTU) in 1996. In 2009, he was offered a scholarship to further his education in Malaysia. He obtained his Ph.D in materials engineering from Universiti Teknologi Malaysia (UTM) in 2012.

From 2013 to 2016, he has been an assistant professor of Materials Engineering at SRTTU. In addition to his regular lecturing and research activities, he has been the director of entrepreneurship and industrial Relations in SRTTU from 2015 so far. He has published over 50 papers mostly in JCR journals. Biodegradable materials, especially magnesium alloys are his current interesting research area.

Dr. H. Jafari was awarded the elected researcher of SRTTU for years 2008, 2011, 2015, and 2016. He also received Best of Best Ph.D student, as well as Chancellor Awards in UTM in 2013. Dr. H. Jafari became the outstanding reviewer for materials and design in 2012-2014. 